\title{
First-price auctions on general preference domains: axiomatic characterizations
}

\author{
Tsuyoshi Adachi • Takumi Kongo
}

Received: 11 February 2013 / Accepted: 9 March 2013 / Published online: 27 March 2013

(C) SAET 2013

\begin{abstract}
In a single-item auction with agents having general preferences, first-price auctions are axiomatically characterized. In this study, we characterize firstprice auctions by Pareto efficiency, individual rationality, anonymity in welfare, and non-bossiness in welfare. The first three properties are satisfied by second-price auctions. Considering the well-known fact that second-price auctions are strategy-proof, a clear distinction between first- and second-price auctions is reducible to the difference between non-bossiness and strategy-proofness, both of which are important properties with respect to agents' strategic behavior. In the characterization, anonymity in welfare can be replaced by envy-freeness, which is also a basic property related to equity among agents. Furthermore, in our characterization, each of the properties, Pareto efficiency, individual rationality, and non-bossiness in welfare, is independent, and domains on which first-price auctions are characterized without equity properties are specified. By strengthening non-bossiness, we characterize first-price auctions by a weaker equity property called equal welfare to equals.
\end{abstract}

Keywords First-price auction - Axiomatic characterization - General preference Non-bossiness · Equity

JEL Classification D44 $\cdot$ D63 $\cdot$ D82

\footnotetext{
T. Adachi

Faculty of Political Science and Economics, Waseda University, 1-6-1 Nishi-Waseda, Shinjuku-ku, Tokyo 169-8050, Japan e-mail: tadachi@aoni.waseda.jp

T. Kongo $(\varangle)$

Faculty of Economics, Fukuoka University, 8-19-1 Nanakuma, Jonan-ku,

Fukuoka 814-0180, Japan

e-mail: kongo@adm.fukuoka-u.ac.jp
} 


\section{Introduction}

In this study, an auction is theoretically studied under a standard setting, an allocation problem of an indivisible item among multiple agents, each of which is interested in obtaining the item by paying some amount of money. ${ }^{1}$ The value of an item being sold differs from agent to agent so that the amount of money they are willing to pay for obtaining the item also differs from agent to agent. By considering every agent's preference on the pair of the item and payment, an auction format decides (1) whether the agent obtains the item and (2) the amount of money each agent pays. ${ }^{2}$

Second-price auctions (Vickrey 1961, generally referred to as Vickrey auctions) and first-price auctions are two well-known auction formats. In both formats, the agent who represents the highest willingness to pay obtains the item (when multiple agents represent the equally highest willingness to pay, a prearranged tie-breaking system is applied to choose one of them); agents who do not obtain the item pay nothing. The difference between the two famous auction formats lies in the payment by the agent who wins the auction. According to the second-price rule, the winner pays the amount of money equal to the second highest willingness to pay among agents, while in first-price auctions, the highest willingness to pay, that is, one's own. This slight difference causes considerable distinctions between properties of the two formats.

Among them, one of the most important properties of second-price auctions is strategy-proofness, which requires that each agent's stating his true preferences does not worsen his welfare. By focusing on strategy-proofness, second-price auctions are axiomatically characterized in various ways (Holmstrom 1979; Chew and Serizawa 2007; Saitoh and Serizawa 2008; Sakai 2008, 2013; Adachi 2012; Ashlagi and Serizawa 2012).

Meanwhile, although their payment rules are simple, first-price auctions have not been well-investigated from an axiomatic point of view. First-price auctions apparently fail to be strategy-proof. Even though his willingness to pay is the highest, an agent representing his true preference obtains essentially nothing, because the agent obtains the item by paying exactly the same amount of money as the value of the item, which is equivalent to obtaining nothing without paying. Thus, ordinarily, every agent is inclined to understate his valuation of the item in first-price auctions. This type of strategic behavior stems from the fact that the winner's payment amount is determined by the winner's willingness to pay.

This self-deterministic payment property in first-price auctions is compatible with non-bossiness (Satterthwaite and Sonnenschein 1981), which is another important property related to agents' strategic behavior. ${ }^{3}$ Non-bossiness requires that an agent stating a false preference has no influence on others unless it influences the agent.

\footnotetext{
1 A recent study by Sakai (2013) also investigates auctions theoretically in an analogous setting.

2 In some auction formats, there is a possibility that agents who do not obtain the item also pay money.

3 Non-bossiness is studied in a wide range of problems in economics, e.g., Serizawa (1996) studies nonbossiness in the economy with a private good and a public good. Kojima (2010) shows the incompatibility between non-bossiness and stability in two-sided matching problems. Morimoto et al. (2013) use nonbossiness to characterize the uniform rule in division problems.
} 
Essentially, first-price auctions have this property. ${ }^{4}$ Obviously, in first-price auctions, the winner is not able to change the outcome for other agents while maintaining himself as a winner. Any agent other than the winner does not change the payment of others unless he becomes a winner; however, in this case, the outcome for the agent has also been changed. In contrast, second-price auctions lack non-bossiness because the payment amount for the winner relies on others' willingness to pay. An agent other than the winner is able to change the winner's payment while keeping the outcome for himself unchanged by increasing his willingness to pay not more than the winner's one but more than the second highest one. Therefore, a clear distinction between secondand first-price auctions is captured by the difference between strategy-proofness and non-bossiness - two major axioms concerning agents' strategic behavior.

In this paper, we present axiomatic characterizations of first-price auctions by focusing on non-bossiness. Together with non-bossiness, other axioms needed for the characterizations are classified into three types: efficiency, equity, and participationconstraint-related axioms. These three types of axioms are basic and important to our results, which suggest that first-price auctions are consequent auction formats when we pay attention to non-bossiness. In particular, our results show that first-price auctions are characterized by (i) strong non-bossiness in welfare, Pareto efficiency, equal welfare to equals, and individual rationality, (ii) non-bossiness in welfare, Pareto efficiency, anonymity in welfare, and individual rationality, (iii) non-bossiness in welfare, envy-freeness (Foley 1967), and individual rationality, and (iv) non-bossiness in welfare, Pareto efficiency, and individual rationality on some restricted domains. Pareto efficiency is a usual requirement in economics. Individual rationality ensures agents' voluntary participation in the auction. Each of the properties, anonymity in welfare, envy freeness, and equal welfare to equals, requires a type of impartial treatment among agents. Thus, (i) is a parallel result to (ii), which strengthens a non-bossy axiom instead of weakening an equity axiom, while (iv) specifies the domains on which we can drop an equity axiom from the set of axioms in (ii).

Also, our results are obtained in a general setting for agents preferences. For agents' preferences, we assume only three basic properties: money monotonicity (less payment is preferable), weak item monotonicity (the auctioned item has non-negative value), and finiteness (the value of the auctioned item is not infinite). We also assume that the domain of agents preferences is not empty (avoid triviality) and is rich (with no spaces between). Our characterizations of first-price auctions on these general-preference domains are in line with recent studies of characterizations of second-price auctions on general-preference domains, such as Saitoh and Serizawa (2008), Sakai (2008, 2013), and Adachi (2012). Importantly, our conditions on preference domains are the most general ones.

The rest of the paper is organized as follows. In Sect. 2, we present our model. In Sect. 3, axioms characterizing first-price auctions are introduced. In Sect. 4, four axiomatic characterizations of first-price auctions are discussed.

\footnotetext{
4 More precisely, we consider non-bossiness in welfare terms, not in the outcome (agents' allotments) itself. Depending on tie-breaking systems, some of the first-price auctions violate non-bossiness in a strict sense. However, in such a case, agents' welfare is never affected; therefore, essentially, it is non-bossy. Detailed discussions of this point are given in Sect. 3 .
} 


\section{Model}

We consider a situation in which a single indivisible item is auctioned. There are multiple and finite agents who are buyers of the auctioned item. The set of agents is denoted by $I$. An allotment of agent $i \in I$ is a pair $\left(x_{i}, t_{i}\right)$, where $x_{i}=0$ or 1 , and $t_{i} \in \mathbf{R}$. Here, $x_{i}=0$ indicates that $i$ does not obtain the auctioned item, $x_{i}=1$ means that $i$ obtains the item, and $t_{i}$ represents that the amount of money that $i$ needs to pay. Each agent $i \in I$ has a preference $\succsim_{i}$, that is a complete and transitive binary relation on the allotment space $\{0,1\} \times \mathbf{R}$. Agent $i$ 's strict and indifferent preferences are denoted by $\succ_{i}$ and $\sim_{i}$, respectively.

We assume three properties for agents' preferences. For every agent $i \in I$ and his preference $\succsim_{i},(\mathrm{i}) \succsim_{i}$ is money monotonic, i.e., for each $x_{i} \in\{0,1\},\left(x_{i}, t_{i}\right) \succ_{i}\left(x_{i}, t_{i}^{\prime}\right)$ if and only if $t_{i}<t_{i}^{\prime}$, (ii) $\succsim_{i}$ is weak item monotonic, i.e., for each $t_{i} \in \mathbf{R},\left(1, t_{i}\right) \succsim_{i}\left(0, t_{i}\right)$, and (iii) $\succsim_{i}$ is finite, i.e., there exists $t_{i} \in \mathbf{R}$ such that $\left(1, t_{i}\right) \sim_{i}(0,0)$. Assumption (i) requires that less payment is always preferable unless the availability of the item is unchanged. Assumption (ii) requires that the auctioned item is a "good" and not a "bad". Assumption (iii) requires that every agent has a critical payment amount for obtaining the auctioned item compared to not obtaining the item and not paying.

Let $\mathcal{P}$ denote the set of all preferences satisfying the above three assumptions. A nonempty subset $\mathcal{D}$ of $\mathcal{P}$ is called a preference domain. Let $v: \mathcal{D} \rightarrow \mathbf{R}$ be the willingness to pay function; that is, for each $\succsim_{i} \in \mathcal{D}$, it holds that $\left(1, v\left(\succsim_{i}\right)\right) \sim_{i}(0,0)$. In other words, $v\left(\succsim_{i}\right)$ represents the greatest amount of money an agent having preference $\succsim_{i}$ is willing to pay to obtain the item. By finiteness of preferences, $v\left(\succsim_{i}\right) \in \mathbf{R}$. By money monotonicity, agents prefer to obtain the item by paying less than $v\left(\succsim_{i}\right)$ and do not prefer to obtain the item by paying more than $v\left(\succsim_{i}\right)$ compared to the allotment $(0,0)$, not obtaining the item without payment. Note that $v\left(\succsim_{i}\right)$ needs to be non-negative by the fact that $(1,0) \succsim_{i}(0,0) \sim_{i}\left(1, v\left(\succsim_{i}\right)\right)$ and money monotonicity.

On preference domains, we assume richness to be defined as follows: for any $\succsim_{i} \in \mathcal{D}$, and any $a \in(0,1)$, there exists $\succsim_{i}^{\prime} \in \mathcal{D}$ such that $v\left(\succsim_{i}^{\prime}\right)=a v\left(\succsim_{i}\right)$. Note that this requirement is essentially the same as the concept of richness introduced by Sakai (2013), which states that the domains of quasi-linear preferences and those of preferences exhibiting positive or negative income effects are typical examples of the rich domains.

Let $\succsim=\left(\succsim_{i}\right)_{i \in I} \in \mathcal{D}^{I}$ be a preference profile, that is the list of every agent's preference. Given $\succsim \in \mathcal{D}^{I},\left(\succsim_{i}^{\prime}, \succsim_{-i}\right)$ is a new preference profile obtained by $i$ 's changing preference from $\succsim_{i}$ to $\succsim_{i}^{\prime} \in \mathcal{D}$.

The auction format or the (auction) rule is a pair of an assignment rule $\hat{x}: \mathcal{D}^{I} \rightarrow$ $\{0,1\}^{I}$ such that $\sum_{i \in I} \hat{x}_{i}(\succsim)=1$ (this requirement is called feasibility) and a payment rule $\hat{t}: \mathcal{D}^{I} \rightarrow \mathbf{R}_{+}^{I}{ }^{5}$ The rule $f=(\hat{x}, \hat{t})$ is a first-price auction if and only if for each $\succsim \in \mathcal{D}^{I}$, and $i \in I$ with $\hat{x}_{i}(\succsim)=1$, (i) $v\left(\succsim_{i}\right)=\max _{j \in I} v\left(\succsim_{j}\right)$, (ii) $\hat{t}_{i}(\succsim)=v\left(\succsim_{i}\right)$,

\footnotetext{
5 Throughout this paper, we do not consider payment rules that allow negative payments to agents (negative payments are considered as rewards to agents). This may seem to be unduly restrictive; however, all our results still hold when we include payment rules that allow negative payments and assume non-negativity of payments (Saitoh and Serizawa 2008) as an axiom instead.
} 
and (iii) $f_{j}(\succsim)=(0,0)$ for each $j \neq i$. In words, a first-price auction is a rule where (i) (one of the) agent(s) representing the highest willingness to pay obtains the auctioned item, (ii) the agent pays exactly the same amount of money as he is willing to pay, and (iii) all other agents pay nothing. Note that depending on the tie-breaking system, which determines the winner among multiple agents representing the highest willingness to pay, several first-price auctions are considered. However, all first-price auctions satisfy the above three properties.

\section{Axioms}

We mention the properties of auction rules as axioms. First, we give two basic axioms. One is Pareto efficiency; the other is individual rationality that induces agents' voluntary participation.

Pareto efficiency (PE): For each $\succsim \in \mathcal{D}^{I}$, there exists no $(x, t) \in\{0,1\}^{I} \times \mathbf{R}^{I}$ with $\sum_{i \in I} x_{i}=1$ and $\sum_{i \in I} t_{i}=\sum_{i \in I} \hat{t}_{i}(\succsim)$ such that for some $i \in I,\left(x_{i}, t_{i}\right) \succ_{i} f_{i}(\succsim)$ and for each $j \in I,\left(x_{j}, t_{j}\right) \succsim_{j} f_{j}(\succsim)$.

Individual rationality (IR): For each $\succsim \in \mathcal{D}^{I}$ and each $i \in I, f_{i}\left(\succsim_{)} \succsim_{i}(0,0)\right.$.

Next, we provide some properties related to fair treatment among agents. Fairness is also a basic property in many allocation problems and is conceptualized in several ways. The following is a fairness property based on anonymity, which focuses on agents' welfare rather than agents' allotments. It requires that swapping preferences between two agents with other agents' preferences unchanged just swaps the two agents' welfare.

Anonymity in welfare (AW): For each $\succsim, \succsim^{\prime} \in \mathcal{D}^{I}$ and each $i, j \in I$, if $\succsim_{i}=\succsim_{j}^{\prime}$, $\succsim_{j}=\succsim_{i}^{\prime}$, and $\succsim_{k}=\succsim_{k}^{\prime}$ for each $k \neq i, j$, then $f_{i}\left(\succsim \sim_{i} f_{j}\left(\succsim^{\prime}\right)\right.$.

Envy-freeness (Foley 1967) is a well-known alternative fairness property. Envyfreeness guarantees that every agent is not jealous of the allotment of the other agent with respect to his preference.

Envy-freeness (EF): For each $\succsim \in \mathcal{D}^{I}$ and each $i, j \in I, f_{i}(\succsim) \succsim_{i} f_{j}(\succsim)$.

An important remark on EF is that in our setting, EF implies PE. ${ }^{6}$ That is, an equity property implies efficiency in this setting.

There is another fairness property that is weaker than the above two. In fact, both AW and EF imply the following general fairness property among agents; this property requires that agents having the same preferences are in the same position with respect to welfare.

Equal welfare to equals (EWE): For each $\succsim \in \mathcal{D}^{I}$ and each $i, j \in I$ such that $\succsim_{i}=\succsim_{j}$, $f_{i}(\succsim) \sim_{i} f_{j}(\succsim)$

\footnotetext{
${ }^{6}$ The proof of Lemma 5 in Sakai (2008) that is derived in restricted domains with respect to ours is also applicable for our setting. Note that the fact that EF implies PE is also mentioned in Svensson (1983) and Alkan et al. (1991).
} 
Next, we introduce a key axiom for characterizations of first-price auctions. Our key axiom is derived from the following non-bossiness axiom, which has been wellinvestigated in various economic problems.

Non-bossiness: For each $\succsim \in \mathcal{D}^{I}$, each $i \in I$, and each $\succsim_{i}^{\prime} \in \mathcal{D}, f_{i}(\succsim)=f_{i}\left(\succsim_{i}^{\prime}, \succsim_{-i}\right)$ implies $f(\succsim)=f\left(\succsim_{i}^{\prime}, \succsim_{-i}\right)$.

As mentioned in Sect. 1, first-price auctions essentially possess non-bossiness, because in first-price auctions, the winner's payment depends only on his willingness to pay. However, depending on the tie-breaking system, several first-price auctions become bossy in a strict sense. Consider the following example.

Example 1 Let $I=\{1,2,3\}$. Consider a first-price auction $f$ having the following tie-breaking system: if the number of agents with the highest willingness to pay is odd, then an agent whose (agent) number is the least acquires the priority to obtain the auctioned item. Otherwise, an agent whose (agent) number is the greatest acquires the priority.

Let the three agents have equal preferences, i.e., $\succsim_{1}=\succsim_{2}=\succsim_{3}$. Following the firstprice auction with the above tie-breaking system, agent 1 obtains the item by paying $v\left(\succsim_{1}\right)$, and 2 and 3 do not obtain it by paying nothing; that is, $f_{1}\left(\succsim_{1}, \succsim_{2}, \succsim_{3}\right)=$ $\left(1, v\left(\succsim_{1}\right)\right)$ and $f_{2}\left(\succsim_{1}, \succsim_{2}, \succsim_{3}\right)=f_{3}\left(\succsim_{1}, \succsim_{2}, \succsim_{3}\right)=(0,0)$.

Now, suppose that agent 2 misstates his preferences as $\succsim_{2}^{\prime}$, where $v\left(\succsim_{2}^{\prime}\right)$ is strictly less than $v\left(\succsim_{1}\right)$ and $v\left(\succsim_{3}\right)$. Thus, 2 is no longer an agent representing the highest willingness to pay. Following the above rule, $f_{3}\left(\succsim_{1}, \succsim_{2}^{\prime}, \succsim_{3}\right)=\left(1, v\left(\succsim_{3}\right)\right)$ and $f_{1}\left(\succsim_{1}, \succsim_{2}^{\prime}, \succsim_{3}\right)=f_{2}\left(\succsim_{1}, \succsim_{2}^{\prime}, \succsim_{3}\right)=(0,0)$. 2 's allotment is as $(0,0)$ as ever. However, 3 obtains the item by paying $v\left(\succsim_{3}\right)$ instead of 1 . Therefore, 2 can change allotments for 1 and 3 while keeping the allotment for himself unchanged.

In the above example, allotments for 1 and 3 are clearly changed between profiles ( $\left.\succsim_{1}, \succsim_{2}, \succsim_{3}\right)$ and $\left(\succsim_{1}, \succsim_{2}^{\prime}, \succsim_{3}\right)$. However, two allotments are equivalent in welfare terms. An agent's having such an influence on the another agent's allotment in firstprice auctions arises only when multiple agents simultaneously announce the highest willingness to pay. In this case, the welfare of each agent is determined by whether $\left(1, v\left(\succsim_{i}\right)\right)$ or $(0,0)$; these are equivalent in welfare by definition. An alternative nonbossiness that is perfectly compatible with first-price auctions with any tie-breaking system is provided by focusing on agents' welfare rather than agents' allotments in the following way.

Non-bossiness in welfare (NBW): For each $\succsim \in \mathcal{D}^{I}$, each $i \in I$, and each $\succsim_{i}^{\prime} \in \mathcal{D}$, $f_{i}(\succsim)=f_{i}\left(\succsim_{i}^{\prime}, \succsim_{-i}\right)$ implies $f_{j}(\succsim) \sim_{j} f_{j}\left(\succsim_{i}^{\prime}, \succsim_{-i}\right)$ for each $j \in I$.

Klaus (2001) also considers the same axiom (under the name of weak non-bossiness in terms of welfare) with the same motivation to study a model of allocating an infinitely divisible commodity. Such a variation in non-bossiness, which focuses on agents' welfare rather than agents' outcomes, is also studied by Mutuswami (2005) in a model of providing a binary good with quasi-linear utilities. The property of Mutuswami (2005) is stronger than NBW in the sense that an agent's intention to have an impact on others is blocked not only when his allotment is unchanged, but also when his 
welfare is unchanged. The natural extension of this property for our model is defined as follows.

Strong non-bossiness in welfare (SNBW): For each $\succsim \in \mathcal{D}^{I}$, each $i \in I$, and each $\succsim_{i}^{\prime} \in \mathcal{D}, f_{i}\left(\succsim \sim_{i} f_{i}\left(\succsim_{i}^{\prime}, \succsim_{-i}\right)\right.$ implies $f_{j}(\succsim) \succsim_{j} f_{j}\left(\succsim_{i}^{\prime}, \succsim_{-i}\right)$ for each $j \in I$.

Note that although SNBW requires that an agent's statement of a false preference only implies other agents' welfare are "not improved", adopting such a weak requirement has no logical effect in the case of NBW since the hypothesis in NBW ("the allotment of $i$ is unchanged") does not distinguish which of $i$ 's two preferences is the true one. ${ }^{7}$

\section{Results}

Using axioms displayed in the previous section, we define four axiomatic characterizations of first-price auctions.

\subsection{Characterization by SNBW}

Before we mention a basic characterization, we give a characterization by SNBW, because its proof is very short and clear.

Lemma 1 If $f$ satisfies $I R$, then for each $\succsim \in \mathcal{D}^{I}$ and each $i \in I, \hat{x}_{i}(\succsim)=0$ implies $f_{i}(\succsim)=(0,0)$.

Proof Suppose the opposite. Then, $f_{i}(\succsim)=\left(0, t_{i}\right)$ with $t_{i}>0$. By money monotonicity, $(0,0) \succ_{i} f_{i}(\succsim)$, which contradicts IR.

Lemma 2 If $f$ satisfies $P E$ and IR, for each $\succsim \in \mathcal{D}^{I}$ and each distinct $i, j \in I$, $\hat{x}_{i}(\succsim)=1$ implies $f_{i}\left(\succsim \succsim_{i}\left(0, \hat{t}_{i}(\succsim)-v\left(\succsim_{j}\right)\right)\right.$.

Proof Let $\succsim \in \mathcal{D}^{I}$ and distinct $i, j \in I$ be such that $\hat{x}_{i}(\succsim)=1$ and $\left(0, \hat{t}_{i}(\succsim)-v\left(\succsim_{j}\right)\right) \succ_{i}$ $f_{i}(\succsim)$. Because $\hat{x}_{i}(\succsim)=1$, by feasibility and Lemma 1 , we have $f_{j}(\succsim)=(0,0)$. Let $\left(x^{\prime}, t^{\prime}\right)$ be such that $\left(x_{i}^{\prime}, t_{i}^{\prime}\right)=\left(0, \hat{t}_{i}(\succsim)-v\left(\succsim_{j}\right)\right),\left(x_{j}^{\prime}, t_{j}^{\prime}\right)=\left(1, v\left(\succsim_{j}\right)\right)$, and $\left(x_{k}^{\prime}, t_{k}^{\prime}\right)=(0,0)$ for each $k \neq i, j$. Then, we have $\left(x_{i}^{\prime}, t_{i}^{\prime}\right) \succ_{i} f_{i}(\succsim)$ and $\left(x_{k}^{\prime}, t_{k}^{\prime}\right) \sim_{k}$ $f_{k}(\succsim)$ for each $k \neq i$, which contradicts PE.

Proposition 1 The first-price auctions are the only rules satisfying SNBW, PE, EWE, and IR.

Proof Obviously, first-price auctions satisfy the four axioms.

Let $f$ satisfy these axioms. Let $\succsim, i$, and $j$ be such that $\hat{x}_{i}(\succsim)=1$ and $\hat{x}_{j}(\succsim)=0$. By Lemma $1, f_{j}(\succsim)=(0,0)$. Let $\succsim_{j}^{\prime}=\succsim_{i}$. By feasibility, there exists $k \in\{i, j\}$ such that $\hat{x}_{k}\left(\succsim_{j}^{\prime}, \succsim_{-j}\right)=0$. By Lemma $1, f_{k}\left(\succsim_{j}^{\prime}, \succsim_{-j}\right)=(0,0)$. By EWE, we have

\footnotetext{
7 The second axiom introduced in Klaus (2001) (under the name of non-bossiness in terms of welfare), which adopts the requirement same as NBW ("other agents' welfare are unchanged") with the same hypothesis in SNBW ("the welfare of $i$ is unchanged"), is strictly stronger than SNBW. Since the first-price auction rules also satisfy this property, they are also characterized with this axiom as a corollary of Proposition 1.
} 
(i) $f_{j}\left(\succsim_{j}^{\prime}, \succsim_{-j}\right) \sim_{j}^{\prime}(0,0)$ and (ii) $f_{i}\left(\succsim_{j}^{\prime}, \succsim_{-j}\right) \sim_{i}(0,0)$. By fact (i) and SNBW, $f_{i}\left(\succsim_{j}^{\prime}, \succsim_{-j}\right) \succsim_{i} f_{i}\left(\succsim_{)}\right.$. By fact (ii), $(0,0) \succsim_{i} f_{i}\left(\succsim_{)}\right.$. By IR, $(0,0) \sim_{i} f_{i}(\succsim$. Because $\hat{x}_{i}(\succsim)=1$, we have $\hat{t}_{i}(\succsim)=v\left(\succsim_{i}\right)$. By Lemma 2 and money monotonicity, it follows that $v\left(\succsim_{i}\right)=\max _{k \in I} v\left(\succsim_{k}\right)$. By Lemma $1, f_{k}(\succsim)=(0,0)$ for each $k \neq i$. Thus, $f$ is the first-price auction rule.

\subsection{Characterization by NBW (basic characterization)}

Basic characterization is performed using non-bossiness with efficiency, equity, and participation-constraint properties. Compared to Proposition 1, we strengthen an equity axiom from EWE to AW and weaken a non-bossy axiom from SNBW to NBW instead.

Proposition 2 The first-price auctions are the only rules satisfying NBW, $P E, A W$, and IR.

Proof Obviously, first-price auctions satisfy the four axioms.

Let $f$ satisfy these axioms. Let $\succsim \in \mathcal{D}^{I}$ and $i \in I$ be such that $\hat{x}_{i}(\succsim)=1$. Because $\hat{x}_{i}(\succsim)=1$, by Lemma $1, f_{j}(\succsim)=(0,0)$ for each $j \neq i$. Let $j \neq i$ and $\succsim_{j}^{\prime}$ be such that $\succsim_{j}^{\prime}=\succsim_{i}$. By AW (by EWE), $f_{i}\left(\succsim_{j}^{\prime}, \succsim_{-j}\right) \sim_{i} f_{j}\left(\succsim_{j}^{\prime}, \succsim_{-j}\right)$. In addition, by feasibility, there exists $k \in\{i, j\}$ such that $\hat{x}_{k}\left(\succsim_{j}^{\prime}, \succsim_{-j}\right)=0$. By Lemma 1 , $f_{k}\left(\succsim_{j}^{\prime}, \succsim_{-j}\right)=(0,0)$. Thus,

$$
f_{i}\left(\succsim_{j}^{\prime}, \succsim_{-j}\right) \sim_{i} f_{j}\left(\succsim_{j}^{\prime}, \succsim_{-j}\right) \sim_{i}(0,0)
$$

If $k=j$, because $f_{j}(\succsim)=(0,0)$, by NBW, $f_{i}(\succsim) \sim_{i} f_{i}\left(\succsim_{j}^{\prime}, \succsim_{-j}\right)$. From (1), $f_{i}(\succsim) \sim_{i}(0,0)$. Because $\hat{x}_{i}(\succsim)=1, \hat{t}_{i}(\succsim)=v\left(\succsim_{i}\right)$.

Suppose that $k=i$. Let $\succsim_{i}^{\prime}=\succsim_{j}$. By AW, $f_{i}\left(\succsim_{)} \sim_{i} f_{j}\left(\succsim_{i}^{\prime}, \succsim_{j}^{\prime}, \succsim_{-i, j}\right)\right.$.

If $\hat{x}_{i}\left(\succsim_{i}^{\prime}, \succsim_{j}^{\prime}, \succsim_{-i, j}\right)=1$, by feasibility, $\hat{x}_{j}\left(\succsim_{i}^{\prime}, \succsim_{j}^{\prime}, \succsim_{-i, j}\right)=0$. By Lemma 1 , $f_{j}\left(\succsim_{i}^{\prime}, \succsim_{j}^{\prime}, \succsim_{-i, j}\right)=(0,0)$. Because $f_{i}(\succsim) \sim_{i} f_{j}\left(\succsim_{i}^{\prime}, \succsim_{j}^{\prime}, \succsim_{-i, j}\right)$, we have $f_{i}\left(\succsim^{\prime} \sim_{i}\right.$ $(0,0)$. Because $\hat{x}_{i}(\succsim)=1, \hat{t}_{i}(\succsim)=v\left(\succsim_{i}\right)$.

If $\hat{x}_{i}\left(\succsim_{i}^{\prime}, \succsim_{j}^{\prime}, \succsim_{-i, j}\right)=0$, by Lemma $1, f_{i}\left(\succsim_{i}^{\prime}, \succsim_{j}^{\prime}, \succsim_{-i, j}\right)=(0,0)$. Because $f_{i}\left(\succsim_{j}^{\prime}\right.$, $\left.\succsim_{-j}\right)=(0,0)$, by NBW, we have $f_{j}\left(\succsim_{i}^{\prime}, \succsim_{j}^{\prime}, \succsim_{-i, j}\right) \sim_{j}^{\prime} f_{j}\left(\succsim_{j}^{\prime}, \succsim_{-j}\right)$. Because $\succsim_{j}^{\prime}=\succsim_{i}$, it follows from (1) that $f_{j}\left(\succsim_{i}^{\prime}, \succsim_{j}^{\prime}, \succsim_{-i, j}\right) \sim_{i}(0,0)$. Because $f_{i}(\succsim) \sim_{i}$ $f_{j}\left(\succsim_{i}^{\prime}, \succsim_{j}^{\prime}, \succsim_{-i, j}\right)$, we have $f_{i}(\succsim) \sim_{i}(0,0)$. Because $\hat{x}_{i}(\succsim)=1, \hat{t}_{i}(\succsim)=v\left(\succsim_{i}\right)$.

Thus, we have $\hat{t}_{i}(\succsim)=v\left(\succsim_{i}\right)$ for every case. By Lemma 2 and money monotonicity, it follows that $v\left(\succsim_{i}\right)=\max _{j \in I} v\left(\succsim_{j}\right)$. By Lemma $1, f_{j}(\succsim)=(0,0)$ for each $j \neq i$. Thus, $f$ is the first-price auction rule.

\subsection{Replacing equity axioms}

AW in Proposition 2 can be replaced with EF. In this case, we can also drop PE from the set of axioms because EF implies it. 
Proposition 3 The first-price auctions are the only rules satisfying NBW, EF, and IR.

Proof Obviously, first-price auctions satisfy the three axioms.

Let $f$ satisfy these axioms. Let $\succsim \in \mathcal{D}^{I}$ and $i, j \in I$ be such that $\hat{x}_{i}(\succsim)=1$ and $\hat{x}_{j}(\succsim)=0$. By Lemma $1, f_{j}(\succsim)=(0,0)$. Suppose that $\hat{t}_{i}(\succsim) \neq v\left(\succsim_{i}\right)$. By IR, $\hat{t}_{i}(\succsim)<v\left(\succsim_{i}\right)$. Note that this implies $f_{i}(\succsim) \succ_{i}(0,0)$. By richness, there exists $\succsim_{j}^{\prime} \in \mathcal{D}$ such that $\hat{t}_{i}(\succsim)<v\left(\succsim_{j}^{\prime}\right)<v\left(\succsim_{i}\right)$.

If $f_{j}\left(\succsim_{j}^{\prime}, \succsim_{-j}\right)=(0,0)$, by NBW, $f_{i}\left(\succsim_{j}^{\prime}, \succsim_{-j}\right) \sim_{i} f_{i}\left(\succsim^{\prime}\right.$. Because $f_{i}(\succsim) \succ_{i}$ $(0,0)$, it follows from Lemma 1 that $\hat{x}_{i}\left(\succsim_{j}^{\prime}, \succsim_{-j}\right)=1$. Because $\hat{x}_{i}(\succsim)$ is also 1 , by money monotonicity, we have $f_{i}\left(\succsim_{j}^{\prime}, \succsim_{-j}\right)=f_{i}(\succsim)$. Because $\hat{t}_{i}\left(\succsim_{j}^{\prime}, \succsim_{-j}\right)=\hat{t}_{i}(\succsim)<$ $v\left(\succsim_{j}^{\prime}\right)$, it follows that $f_{i}\left(\succsim_{j}^{\prime}, \succsim_{-j}\right) \succ_{j}^{\prime}(0,0)=f_{j}\left(\succsim_{j}^{\prime}, \succsim_{-j}\right)$, which contradicts EF.

Thus, $f_{j}\left(\succsim_{j}^{\prime}, \succsim_{-j}\right) \neq(0,0)$. By feasibility and Lemma 1 , (i) $\hat{x}_{j}\left(\succsim_{j}^{\prime}, \succsim_{-j}\right)=1$ and (ii) $f_{i}\left(\succsim_{j}^{\prime}, \succsim_{-j}\right)=(0,0)$. By IR and fact (i), we have $\hat{t}_{j}\left(\succsim_{j}^{\prime}, \succsim_{-j}\right) \leq v\left(\succsim_{j}^{\prime}\right)$. Because $v\left(\succsim_{j}^{\prime}\right)<v\left(\succsim_{i}\right)$, it follows from fact (ii) that $f_{j}\left(\succsim_{j}^{\prime}, \succsim_{-j}\right) \succ_{i}(0,0)=f_{i}\left(\succsim_{j}^{\prime}, \succsim_{-j}\right)$, which contradicts EF. Thus, we have $\hat{t}_{i}\left(\succsim_{)}=v\left(\succsim_{i}\right)\right.$.

By Lemma 2 and money monotonicity, it follows that $v\left(\succsim_{i}\right)=\max _{k \in I} v\left(\succsim_{k}\right)$. By Lemma $1, f_{k}(\succsim)=(0,0)$ for each $k \neq i$. Thus, $f$ is the first-price auction rule.

\subsection{Independence of axioms other than equity}

This subsection discusses redundancy of axioms other than equity in our characterizations. Each axiom of (S)NBW, PE, and IR in Propositions 1-3 is independent of the other axioms. Propositions 1-3 are obtained in general domains that are non-empty and rich; thus, it is possible to consider unnatural domains. With respect to the independence of axioms, we focus more on some domains that are intuitive, if needed.

For independence of (S)NBW, consider the second-price auction, i.e., the rule $f=$ $(\hat{x}, \hat{t})$ where for each $\succsim \in \mathcal{D}^{I}$, and $i \in I$ with $\hat{x}_{i}(\succsim)=1$, (i) $v\left(\succsim_{i}\right)=\max _{j \in I} v\left(\succsim_{j}\right)$, (ii) $\hat{t}_{i}(\succsim)=\max _{j \in I \backslash\{i\}} v\left(\succsim_{j}\right)$, and (iii) $f_{j}(\succsim)=(0,0)$ for each $j \neq i$. This rule completely satisfies PE, AW, EF, EWE, and IR but not (S)NBW.

For independence of $\mathrm{PE}$, consider a rule in which a specific agent $i \in I$ always obtains the auctioned item by paying his willingness to pay, while others pay nothing. This rule obviously lacks PE; however, it possesses (S)NBW, AW, EWE, and IR. Note that lack of PE implies a lack of EF.

For independence of IR, consider a first-price auction with positive participation fees, i.e., a rule $f=(\hat{x}, \hat{t})$ where for each $\succsim \in \mathcal{D}^{I}$ and $i \in I$ with $\hat{x}_{i}(\succsim)=1$, (i) $v^{\epsilon}\left(\succsim_{i}\right)=\max _{j \in I} v^{\epsilon}\left(\succsim_{j}\right)$, (ii) $\hat{t}_{i}\left(\succsim_{)}=v^{\epsilon}\left(\succsim_{i}\right)+\epsilon\right.$, and (iii) $f_{j}(\succsim)=(0, \epsilon)$ for each $j \neq i$, where $\epsilon>0$ and $v^{\epsilon}\left(\succsim_{i}\right)$ satisfies $\left(1, \epsilon+v^{\epsilon}\left(\succsim_{i}\right)\right) \sim_{i}(0, \epsilon){ }^{8}$. This rule satisfies (S)NBW, PE, AW, EF, and EWE, but not IR.

\footnotetext{
${ }^{8}$ It is worth mentioning that on certain types of domains, this rule is not well-defined, because agents' willingness to pay under the existence of participation fees (i.e., $\left.v^{\epsilon}\left(\succsim_{i}\right) \in \mathbf{R}\right)$ may not be determined. However, such domains are very anomalistic. Once we assume that preferences are continuous (Saitoh and Serizawa 2008; Adachi 2012), then first-price auctions with participation fees are well-defined on any domain. Alternatively, assuming that domains must contain the set of all quasi-linear preferences (Sakai 2008) or adding a condition for richness (Sakai 2013), we can consider another rule showing that IR is independent, even though first-price auctions with participation fees might not be well-defined on any domain.
} 


\subsection{Dropping equity axioms}

On some of our general domains of agents' preferences, there is a possibility that characterization holds without equity axioms. This means that on some domains, AW is redundant for Proposition 2 and EF is exchangeable by PE for Proposition 3. However, such domains are special and are defined as follows. Let

$$
\begin{aligned}
\mathcal{P}_{-}= & \left\{\succsim_{i} \in \mathcal{P} \mid \text { for any } t_{i}<v\left(\succsim_{i}\right) \text { with } t_{i} \geq 0,\right. \\
& \text { there exists } \left.a<v\left(\succsim_{i}\right) \text { such that }\left(0, t_{i}-a\right) \succ_{i}\left(1, t_{i}\right)\right\} .
\end{aligned}
$$

Intuitively speaking, $\mathcal{P}_{-}$is the set of preferences with properly negative income effects when we consider $(0,0)$ as the reference point.

If $\mathcal{D} \nsubseteq \mathcal{P}_{-}$, then the following rule $f^{+}$satisfies NBW, PE, EWE, and IR: let $\succsim_{i}^{+}$ and $t_{i}<v\left(\succsim_{i}^{+}\right)$with $t_{i} \geq 0$ be such that for each $a<v\left(\succsim^{+}\right),\left(1, t_{i}\right) \succsim_{i}\left(0, t_{i}-a\right)$. Select $i \in I$. Now, for each $\succsim \in \mathcal{D}^{I}$, If $\succsim_{i}=\succsim_{i}^{+}$and $v\left(\succsim_{i}^{+}\right)>v\left(\succsim_{j}\right)$ for each $j \neq i$, then $f_{i}^{+}(\succsim)=\left(1, t_{i}\right)$ and $f_{j}^{+}(\succsim)=(0,0)$ for each $j \neq i$. Otherwise, $f^{+}$follows a first-price auction with a tie-breaking system in which $i$ is the lowest priority.

Thus, we cannot obtain the characterization result without equity axioms if $\mathcal{D} \nsubseteq$ $\mathcal{P}_{-}$. Actually, this condition is also a sufficient condition to obtain the characterization result without equity axioms.

Proposition 4 The first-price auctions are the only rules satisfying NBW, PE, and IR if and only if $\mathcal{D} \subseteq \mathcal{P}_{-}$.

Proof Let $\mathcal{D} \subseteq \mathcal{P}_{-}$and $f$ satisfy these axioms. Let $\succsim, i$, and $j$ be such that $\hat{x}_{i}(\succsim)=1$ and $\hat{x}_{j}(\succsim)=0$. By Lemma $1, f_{j}(\succsim)=(0,0)$. Suppose that $\hat{t}_{i}(\succsim) \neq v\left(\succsim_{i}\right)$. By IR, $\hat{t}_{i}(\succsim)<v\left(\succsim_{i}\right)$. Note that this implies $f_{i}\left(\succsim \succ_{i}(0,0)\right.$. Because $\succsim_{i} \in \mathcal{P}_{-}$, there exists $a<v\left(\succsim_{i}\right)$ such that $\left(0, \hat{t}_{i}(\succsim)-a\right) \succ_{i} f_{i}(\succsim)$. By richness, there exists $\succsim_{j}^{\prime} \in \mathcal{D}$ such that $a<v\left(\succsim_{j}^{\prime}\right)<v\left(\succsim_{i}\right)$.

If $f_{j}\left(\succsim_{j}^{\prime}, \succsim_{-j}\right)=(0,0)$, by NBW, $f_{i}\left(\succsim_{j}^{\prime}, \succsim_{-j}\right) \sim_{i} f_{i}\left(\succsim^{\prime}\right.$. Because $f_{i}\left(\succsim^{\prime} \succ_{i}\right.$ $(0,0)$, it follows from Lemma 1 and money monotonicity that $f_{i}\left(\succsim_{j}^{\prime}, \succsim_{-j}\right)=f_{i}\left(\succsim_{)}\right.$. Because $\left(0, \hat{t}_{i}(\succsim)-a\right) \succ_{i} f_{i}(\succsim)$, we have $\left(0, \hat{t}_{i}\left(\succsim_{j}^{\prime}, \succsim_{-j}\right)-a\right) \succ_{i} f_{i}\left(\succsim_{j}^{\prime}, \succsim_{-j}\right)$. Because $v\left(\succsim_{j}^{\prime}\right)>a,\left(0, \hat{t}_{i}\left(\succsim_{j}^{\prime}, \succsim_{-j}\right)-v\left(\succsim_{j}^{\prime}\right)\right) \succ_{i} f_{i}\left(\succsim_{j}^{\prime}, \succsim_{-j}\right)$, which contradicts Lemma 2.

Thus, $f_{j}\left(\succsim_{j}^{\prime}, \succsim_{-j}\right) \neq(0,0)$. By feasibility and Lemma 1 , (i) $\hat{x}_{j}\left(\succsim_{j}^{\prime}, \succsim_{-j}\right)=1$ and (ii) $f_{i}\left(\succsim_{j}^{\prime}, \succsim_{-j}\right)=(0,0)$. By IR and fact (i), we have $\hat{t}_{j}\left(\succsim_{j}^{\prime}, \succsim_{-j}\right) \leq v\left(\succsim_{j}^{\prime}\right)$. If $\hat{t}_{j}\left(\succsim_{j}^{\prime}, \succsim_{-j}\right)=v\left(\succsim_{j}^{\prime}\right)$, because $f_{j}\left(\succsim_{j}^{\prime}, \succsim_{-j}\right) \sim_{j}^{\prime}(0,0)$, we have $\left(0, \hat{t}_{j}\left(\succsim_{j}^{\prime}, \succsim_{-j}\right)\right.$ $\left.-v\left(\succsim_{j}^{\prime}\right)\right) \sim_{j}^{\prime} f_{j}\left(\succsim_{j}^{\prime}, \succsim_{-j}\right)$. If $\hat{t}_{j}\left(\succsim_{j}^{\prime}, \succsim_{-j}\right)<v\left(\succsim_{j}^{\prime}\right)$, because $\succsim_{j}^{\prime} \in \mathcal{P}_{-}$, we have $\left(0, \hat{t}_{j}\left(\succsim_{j}^{\prime}, \succsim_{-j}\right)-v\left(\succsim_{j}^{\prime}\right)\right) \succ_{j}^{\prime} f_{j}\left(\succsim_{j}^{\prime}, \succsim_{-j}\right)$. Thus, $\left(0, \hat{t}_{j}\left(\succsim_{j}^{\prime}, \succsim_{-j}\right)-v\left(\succsim_{j}^{\prime}\right)\right) \succsim_{j}^{\prime}$ $f_{j}\left(\succsim_{j}^{\prime}, \succsim_{-j}\right)$ for every case. Because $v\left(\succsim_{i}\right)>v\left(\succsim_{j}^{\prime}\right)$, it follows that $\left(0, \hat{t}_{j}\left(\succsim_{j}^{\prime}\right.\right.$, $\left.\left.\succsim_{-j}\right)-v\left(\succsim_{i}\right)\right) \succ_{j}^{\prime} f_{i}\left(\succsim_{j}^{\prime}, \succsim_{-j}\right)$, which contradicts Lemma 2 .

Thus, $\hat{t}_{i}(\succsim)=v\left(\succsim_{i}\right)$. By Lemma 2 and money monotonicity, it follows that $v\left(\succsim_{i}\right)$ $=\max _{k \in I} v\left(\succsim_{k}\right)$. By Lemma $1, f_{k}(\succsim)=(0,0)$ for each $k \neq i$. Thus, $f$ is the first-price auction rule. 
Note that $f^{+}$satisfies EWE. Thus, we obtain the following corollary.

Corollary 1 The first-price auctions are the only rules satisfying NBW, PE, EWE, and IR if and only if $\mathcal{D} \subseteq \mathcal{P}_{-}$.

In this sense, we can also say that the characterizations in Propositions 2 and 3 are tight.

It is difficult to perfectly characterize under which condition EWE is independent from the other axioms in Proposition 1. We mention facts on well-investigated domains: if a domain $\mathcal{D}$ is a set composed only of quasi-linear preferences or preferences that exhibit positive income effect, then EWE is independent of the set of axioms in Proposition 1, while it is redundant if $\mathcal{D} \subseteq \mathcal{P}_{-}$.

Acknowledgments The authors appreciate an anonymous referee for his/her comments and suggestions. This study is supported by JSPS KAKENHI Grant Number 23830087 (Adachi), 24730174 (Kongo).

\section{References}

Adachi, T.: Equity and the Vickrey allocation rule on general preference domain (2012) (Mimeo)

Alkan, A., Demange, G., Gale, D.: Fair allocation of indivisible goods and criteria of justice. Econometrica 59, 1023-1039 (1991)

Ashlagi, I., Serizawa, S.: Characterizing Vickrey allocation rule by anonymity. Soc. Choice Welf. 38, 531542 (2012)

Chew, S.H., Serizawa, S.: Characterizing the Vickrey combinatorial auction by induction. Econ. Theory 33, 393-406 (2007)

Foley, D.: Resource allocation and the public sector. Yale Econ. Essays 7, 45-98 (1967)

Holmstrom, B.: Grove's scheme on restricted domains. Econometrica 47, 1137-1144 (1979)

Klaus, B.: Coalitional strategy-proofness in economies with single-dipped preferences and the assignment of an indivisible object. Games Econ. Behav. 34, 64-82 (2001)

Kojima, F.: Impossibility of stable and nonbossy matching mechanisms. Econ. Lett. 107, 69-70 (2010)

Morimoto, S., Serizawa, S., Ching, S.: A characterization of the uniform rule with several commodities and agents. Soc. Choice Welf. 40, 871-911 (2013)

Mutuswami, S.: Strategyproofness, non-bossiness and group strategyproofness in a cost sharing model. Econ. Lett. 89, 83-88 (2005)

Saitoh, H., Serizawa, S.: Vickrey allocation rule with income effect. Econ. Theory 35, 391-401 (2008)

Sakai, T.: Second price auctions on general preference domains: two characterizations. Econ. Theory 37, 347-356 (2008)

Sakai, T.: An equity characterization of second price auctions when preferences may not be quasilinear. Rev. Econ Design 17, 17-26 (2013)

Satterthwaite, M.A., Sonnenschein, H.: Strategy-proof allocation mechanisms at differentiable points. Rev. Econ. Stud. 48, 587-597 (1981)

Serizawa, S.: Strategy-proof and individually rational social choice functions for public good economies. Econ. Theory 7, 501-512 (1996)

Svensson, L.G.: Large indivisibles: an analysis with respect to price equilibrium and fairness. Econometrica 51, 939-954 (1983)

Vickrey, W.: Counterspeculation, auctions, and competitive sealed tenders. J. Finance 16, 8-37 (1961) 